\title{
Seismic shear demands in columns of RC frames accounting for dynamic amplification effects
}

\section{Demandas sísmicas de corte en columnas de marcos de hormigón armado incluyendo efectos} dinámicos

Fecha de entrega: 28 de octubre 2019 Fecha de aceptación: 19 de noviembre 2019

\section{Patricio Quintana Gallo}

Escuela de Ingeniería Civil, Universidad de Valparaíso, General Cruz 222, Piso 4, Valparaíso, Chile, patricio.quintana@uv.cl

This article presents a numerical study on the shear force demands suffered by columns of reinforced concrete $(R C)$ frames subjected to seismic actions. The paper examines well established capacity-based design procedures which account for dynamic amplification effects via the dynamic magnification factor $\omega_{v}$, which multiplies the static shear demands resulting from the development of the beam flexural strengths. It also reviews the prescriptions of the New Zealand Standard NZS3101, which requires $\omega_{v}=1.3$ for columns of intermediate storeys. Using the results of nonlinear dynamic analyses (NLDA) of a model representing one of the main directions of a 12-storey building structured with $R C$ walls and special moment resisting frames designed per NCh433 and ACI318, the paper shows the calculated values of $\omega_{v}$ for different column types and storey level, as subjected to a set of 13 earthquake records. The results show that $1.0<\omega_{v}<1.3$ in the great majority of the cases, suggesting that the limit $\omega_{v}=1.3$ would be appropriate in this particular case. However, it cannot be considered a conservative upper bound in a conclusive way, because values as large as 1.6 were predicted in some of the cases. Acknowledging that no dynamic amplification effects are included in the calculation of the capacity-based shear demands for columns of frames according to ACI318 (current 2019 edition), it is proposed that the recommendation of NZS3101 (2006), which cover such effects, are included in the upcoming edition of the Chilean Standard NCh430.

Keywords: reinforced concrete (RC), seismic shear demands, columns, dynamic amplification
Este artículo presenta un estudio numérico sobre las demandas de corte sufridas por columnas de marcos de hormigón armado sujetas a acciones sísmicas. El trabajo examina procedimientos bien establecidos de diseño al corte por capacidad que incluyen efectos de amplificación dinámica mediante el factor $\omega_{v}$ que multiplica la fuerza de corte estática asociada al desarrollo de la resistencia en flexión de las vigas. También revisa los requisitos de la norma neozelandesa NZS3101 que requiere usar $\omega_{v}=1.3$ para columnas de pisos intermedios. Usando los resultados de análisis dinámicos no-lineales de un modelo que representa una de las direcciones principales de un edificio de 12 pisos estructurado con muros $y$ marcos de hormigón armado diseñados según NCh433 y ACI318, el artículo muestra los valores calculados de $\omega_{v}$ para distintos tipos de columnas y pisos, cuando es sometido a un set de 13 registros sísmicos. Los resultados indicaron que $1.0<\omega_{v}<1.3$ en la gran mayoría de los casos, sugiriendo que el límite $\omega_{v}=1.3$ sería apropiado en este caso. Sin embargo, este valor no puede considerarse una cota superior dado que en algunos casos se obtuvo valores de hasta 1.6. Reconociendo que el efecto de amplificación dinámica no se incluye en el cálculo de la demanda de corte por capacidad estipulada por ACI318 (incluyendo su edición 2019), se propone que se consideren los requisitos de la norma neozelandesa NZS3101 para ser incluidos en los requerimientos de la norma chilena NCh430.

Palabras clave: hormigón armado, demandas sísmicas de corte, columnas, amplificación dinámica

\section{Introduction}

Seismically induced shear demands expected for reinforced concrete (RC) structural members have been broadly studied in the past. Amongst research involving such topic, the work done at the University of Canterbury, synthesized in Paulay and Priestley (1992), sets up a paramount milestone when formally defining capacity-based seismic design for RC walls and frames. The virtue of this design philosophy is the seeking for independence from the seismic demand, when acknowledging the complexity of 
the earthquake phenomenon (Paulay, 1983).

This nowadays well-known design philosophy was firstly incorporated in the New Zealand RC design standard NZS3101 (1995). In particular, the capacity design principles and formulations for shear are provided for wall, frame, and wall-frame buildings. Such principles include considerations on the hierarchy of the strengths within the system to impose a desired inelastic mechanism and failure mode. Static equilibrium of the internal forces and moments, resulting from deflections which impose such mechanism, are used for relating the flexural capacity of critical sections of walls or beams and columns to the shear force demand in walls, columns, beams, and beam-column joints, as corresponds. Further, the shear demands obtained with consideration on statics, are amplified to account for dynamic effects (see e.g. Goodsir et al., 1983 and Quintana Gallo 2008, 2018).

The code ACI318 (1995) on the other hand, had traditionally not used this method, except for frames, in a simplified version, included from the 1995 edition onward. For structural walls, the ACI318 code included a smaller reduction factor for shear resistance under seismic actions of 0.6 (instead of the normal 0.85 ), but the required seismic shear $V_{u}$ was still obtained with a code-prescribed elastic analysis. The ACI318 (2019) version, however, requires the use of a capacity-based design for shear, adopting what is stipulated in the New Zealand standard NZS3101 (2006), with minor modifications, such as: (1) the use of a minimum over-strength factor $\Omega_{0}=M_{p l} / M_{u}=1.5$; and (2) a limit of $3 V_{u}$ for the shear obtained with the procedure. The dynamic amplification factor $\omega_{\mathrm{v}}$ is included using the same expression of Paulay and Priestley (1992) and $\mathrm{NZS} 3101$, i.e. as a function of the number of stories $n$ and with a maximum value of 1.8. This constitutes an evident improvement in the rationality of the procedure used for estimating the shear demands on walls, which affects Chile, as the code prescriptions of ACI318 have been traditionally adopted for the design of RC structures in such country, with minor supposedly well-backgrounded exceptions and alternative procedures stated in the Chilean RC code NCh430 (2008).

For frames, in turn, ACI318 (2019) does not include new features, besides a more rational explanation of the calculations involved in the design of beam-column joints.
This is, the part of the original and NZS3101 formulations related to dynamic amplification effects that is still not adopted. Dynamic amplification affects two aspects of the design of a frame: (1) securing of the strong column-weak beam principle in beam column joints (desired hierarchy of strengths); and (2) the calculation of the shear forces in columns.

To investigate if the amplification of the shear forces of special moment resisting frames, part of wall-frame buildings in particular, this work presents the results of a series of non-linear dynamic analyses (NLDA) of a 12-storey ideal building structured with T-shaped walls and special moment resisting frames, designed per the Chilean seismic code NCh433 (1996) and ACI318 (2005), part of the work presented in Quintana Gallo (2008). The results of the NLDA, obtained for several earthquake records, show how the shear demand obtained with purely static capacity-design considerations is exceeded in most of the cases. The results also show that the dynamic amplification factor required by NZS3101 seems appropriate, but not in all of the cases.

\section{Static capacity-based shear demand Columns of intermediate storeys}

The shear demands in the top and bottom columns of intermediate storeys (i.e. not the first and top levels) are related to the shear demands in the beams framing into the columns by static equilibrium considerations. Figure 1 presents the free-body equilibrium diagram of an interior beam-column joint, drawn to match the inflexion points of beams and columns under equivalent lateral forces (denoted with the subscript " $E$ "), such that $l_{i, c}^{T}, l_{i, c}^{B}, l_{i, b}^{L}$, and $l_{i, c}^{T}$ correspond to the distance from the point of contraflexure at the top and bottom columns, and left and right-hand side beams, to the intersection of the centrelines, respectively. With reference in Figure 1, by equilibrium of horizontal and vertical forces:

$$
\begin{aligned}
& V_{E, c}^{T}=V_{E . c}^{B}=V_{E, c} \\
& V_{E . b}^{L}-V_{E . b}^{R}=\Delta N_{E}
\end{aligned}
$$

where $V_{E, c}^{T}$ and $V_{E . c}^{B}$ are the shear forces at the top and bottom columns, respectively (both equal to $V_{E, c}$, since differences in the axial load of the beams are neglected), 
$V_{E, b}^{L}$ and $V_{E . b}^{R}$ are the shear forces at the left and right-hand side beams, respectively. The term $\Delta N_{E, c}$ is the axial load variation in the column, and corresponds to the difference between the shear in the beams at both sides of the column. Note that the axial load in the top column, $N_{E, c}^{T}$, is assumed not to change due to gravity effects introduced at the floor level due to the weight of the slab or others.

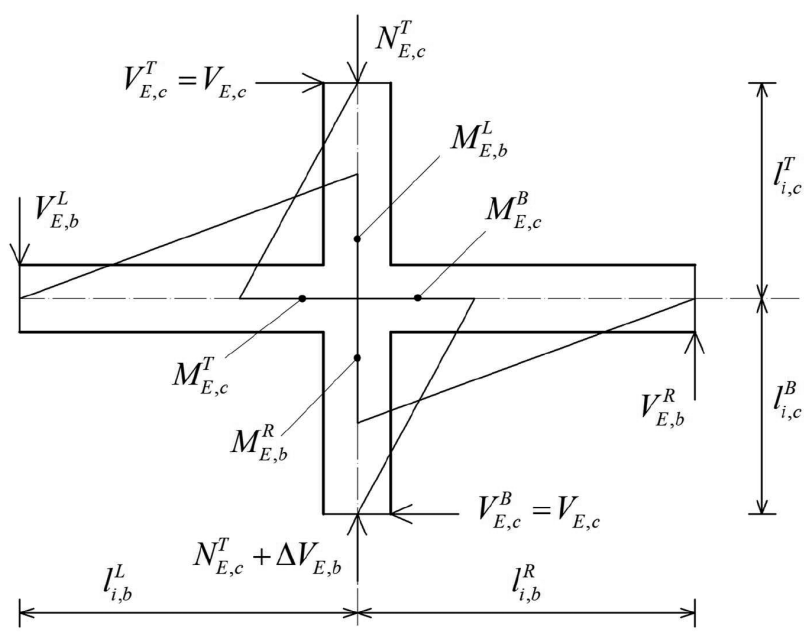

Figure 1: Free-body equilibrium in an interior beam-column joint

As in general $l_{i, c}^{T} \neq l_{i, c}^{B}$, the top/column moments at the intersection with the beams (measured at the centrelines), $M_{E c}^{T}$ and $M_{E c}^{B}$, are not necessarily identical. In fact, $l_{i, c}^{T}=l_{i, c}^{B}$ occurs only when $M_{E c}^{T}=M_{E c}^{B}$, because as $V_{E, c}^{T}=V_{E, c}^{B}, l_{i, c}^{T} / l_{i, c}{ }^{B}$ $=M_{E c}^{T} / M_{E c}^{T}$ must be respected. By equilibrium of moments relative to the centre of the joint, equation (3) is obtained:

$$
V_{E, c}=\frac{V_{E, b}^{L} l_{i, b}^{L}+V_{E, b}^{R} l_{i, b}^{R}}{\left(l_{i, c}^{T}+l_{i, c}^{B}\right)}
$$

Additionally, it holds that $V_{E, b}^{L} l_{i, b}^{L}=M_{E, b}^{L}$ and $V_{E, b}^{R} l_{i, b}^{R}=M_{E, b}^{R}$, which replaced in (3) leads to (4):

$$
V_{E, c}=\frac{M_{E, b}^{L}+M_{E, b}^{R}}{\left(l_{i, c}^{T}+l_{i, c}^{B}\right)}
$$

Equation (4) relates the shear in the columns as a function of the moments in the beams and the inflexion-point lengths, measured at the centreline of the column. To refer the beam moments to the faces of the column (with crosssection height $h_{c}$ ), it is recalled that the slope of the moment diagram along the beams corresponds to the shear force, such that:

$$
\begin{aligned}
& M_{E, b}^{R, f}=M_{E, b}^{R}-V_{E, b}^{R} h_{c} / 2 \\
& M_{E, b}^{L, f}=M_{E, b}^{L}-V_{E, b}^{L} h_{c} / 2
\end{aligned}
$$

In equations (5) and (6) the $f$ in the superscript refers to 'face' (of the column). Using these expressions instead of $M_{E, b}^{L}$ and $M_{E, b}^{R}$ in (4) leads to equation (7):

$$
V_{E, c}=\frac{M_{E, b}^{L}+M_{E, b}^{R}-h_{c}\left(\frac{V_{E, b}^{L}+V_{E, b}^{R}}{2}\right)}{\left(l_{i, c}^{T}+l_{i, c}^{B}\right)}
$$

The calculation of $V_{E, c}$ with (7) requires knowledge of the shear in the beams, which in turn depends on the moments at the other beam ends. To examine the magnitude of this term, it is assumed that the moments at such ends are equal to the moments at the opposite face of the columns under investigation, and that the beam spans are identical and equal to $l_{b}$ (measured to the centrelines). Under this assumptions, it holds that $V_{E, b}^{L}=\left(M_{E, b}^{L}+M_{E, b}^{R}\right) / l_{b}$ and $V_{E, b}^{L}=$ $\left(M_{E, b}^{R}+M_{E, b}^{L}\right) / l_{b}$. Replacing these expression in (7) yields:

$$
V_{E, c}=\frac{\left(M_{E, b}^{L}+M_{E, b}^{R}\right)\left(1-h_{c} / l_{b}\right)}{\left(l_{i, c}^{T}+l_{i, c}^{B}\right)}
$$

The term $h_{c} / l_{b}$ is normally small as the elements of a frame are slender by definition, but can be of relevance for short deep beams. In any case, neglecting such term is on the conservative side, and is dropped in the calculation of the shear force demands in the column. This is, (4) is preferred over (8). After the flexural capacity of the beams (including overstrength) has developed, the moments in the beams are known and are related to the moment required by the analysis according to (9) and (10):

$$
\begin{aligned}
& M_{o, b}^{R}=\Omega_{0, b}^{R} M_{E, b}^{R} \\
& M_{o, b}^{L}=\Omega_{0, b}^{L} M_{E, b}^{L}
\end{aligned}
$$

where $\Omega_{0, b}^{L}$ and $\Omega_{0, b}^{R}$ are the flexural overstrength factors of the left and right-side beams, respectively. Note that these two values are not necessarily the same, as the overstrength factor is normally larger for negative than for positive moments, mostly due to the effect of the reinforcing steel of the floor slab. Replacing (9) and (10) into (4) leads to (11): 


$$
V_{E, c}=\frac{M_{o, b}^{L} / \Omega_{0, b}^{L}+M_{o, b}^{R} / \Omega_{0, b}^{R}}{\left(l_{i, c}^{T}+l_{i, c}^{B}\right)}
$$

The shear in the column at beam flexural overstrength can be directly calculated using (12), which is analogous to (4).

$$
V_{o, c}=\frac{M_{o, b}^{L}+M_{o, b}^{R}}{l_{i, c}^{T}+l_{i, c}^{B}}
$$

To relate the elastic shear $V_{E, c}$ to $V_{o, c}$, the overstrength factor $\Omega_{0, c}$ is introduced, as defined in (13).

$$
V_{o, c}=\Omega_{0, c} V_{E, c}
$$

Combining equations (12) and (13), $\Omega_{0, c}$ can be expressed as in (14):

$$
\Omega_{0, c}=\frac{M_{o, b}^{L}+M_{o, b}^{R}}{M_{o, b}^{L} / \Omega_{0, b}^{L}+M_{o, b}^{R} / \Omega_{0, b}^{R}}
$$

Further, replacing (9) and (10) into (14) leads to (15):

$$
\Omega_{0, c}=\frac{M_{o, b}^{L}+M_{o, b}^{R}}{M_{E, b}^{L}+M_{E, b}^{R}}
$$

NZS3101 (2006) allows using $\Omega_{0, c}$ equal to the mean average of the beam overstrength factors, $\Omega_{0, b}^{a v g}$, such that:

$$
\Omega_{0, c}=\Omega_{0, c}^{a v g}=\left(\Omega_{o, b}^{L}+\Omega_{o, b}^{R}\right) / 2
$$

Substituting (15) into (16) to impose such assumption, and using (9) and (10), leads to (17):

$$
\frac{M_{E, b}^{L} \Omega_{0, b}^{L}+M_{E, b}^{R} \Omega_{0, b}^{R}}{M_{E, b}^{L} \Omega_{0, b}^{R}+M_{E, b}^{R} \Omega_{0, b}^{L}}=1
$$

Equation (17) can be reduced to (18):

$$
M_{E, b}^{L}=M_{E, b}^{R}
$$

Hence, the assumption of NZS3101 (2006) stated in (16) is compatible with (15) only when the elastic moments required in the beams are identical. However, if such moments are different to each other, $\Omega_{0, b}^{\text {avg }}$ can be smaller than $\Omega_{0, c}$ calculated per (17), depending on the ratio $\Omega_{0, b}^{L} /$ $\Omega_{0, b}^{R}$. Referring the beam elastic moments and overstrength factors to the reference parameters $M_{E, b}$ and $\Omega_{0, b}$, such that $M_{E, b}^{L}=\alpha M_{E, b}^{R}=\alpha M_{E, b}$, and $\Omega_{0, b}^{L}=\beta \Omega_{0, b}^{R}=\beta \Omega_{0, b}$ (with $\alpha>1$ and $\beta>1$ ), equation (15) can be written as (19):

$$
\Omega_{0, c}=\Omega_{0, b} \frac{(\alpha \beta+1)}{(1+\alpha)}
$$

The parameter $\Omega_{0, b}^{\text {avg }}$ in (16), on the other hand, is re-written as in (20):

$$
\Omega_{0, b}^{a v g}=\Omega_{0, b} \frac{(\beta+1)}{2}
$$

Dividing (19) into (20) to calculate the ratio $\gamma=\Omega_{0, b} / \Omega_{0, b}^{a v g}$ and evaluate how unconservative (16) can be, equation (21) is obtained.

$$
\gamma=\frac{\Omega_{0, c}}{\Omega_{0, b}^{a v g}}=\frac{2(\alpha \beta+1)}{(1+\alpha)(1+2)}
$$

Numerical inspection of (21) leads to $\gamma=1.11$ for $\alpha=2$ and $\beta=2$, and $\gamma=1.20$ for $\alpha=2$ and $\beta=4$. Thus, using the recommendation of NZS3101 (2006) will provide a slightly smaller column overstrength factor than that obtained with (15) or (19) for normal cases, but might be unconservative for exceptional cases. Hence, it is recommended that the latter equations be directly used in the calculations.

Finally, for the particular case where $M_{0, b}^{L}=M_{0, b}^{R}=M_{0, b}^{R},(15)$ reduces to (22):

$$
\Omega_{0, c}=\frac{2 \Omega_{o, b}^{L} \Omega_{o, b}^{R}}{\Omega_{0, b}^{L}+\Omega_{0, b}^{R}}
$$

If, additionally, $M_{E, b}^{L}=M_{E, b}^{R}=M_{E, b}$, implying that $\Omega_{0, b}^{L}=\Omega_{0, b}^{R}$ $=\Omega_{0, b}$, equation (23) is obtained, which corresponds to the generic case presented in Paulay and Priestley (1992).

$$
\Omega_{0, c}=\Omega_{0, b}
$$

For the general case, combining (12) with (15) leads to (24):

$$
V_{o, c}=\left(\frac{M_{o, b}^{L}+M_{o, b}^{R}}{M_{E, b}^{L}+M_{E, b}^{R}}\right) V_{E, c}
$$


It is shown that for the calculation of $V_{o, c}$ per (24), in addition to the beam flexural capacities, the elastic shear and moment demands obtained with the analysis $\left(V_{E, c}\right.$, $\left.M_{E, b}^{L}, M_{E, b}^{R}\right)$ are needed. On the other hand, (12) implies knowledge of $l_{i, c}^{B}$ and $l_{i, c}^{T}$. Noting both equations are equivalent while (24) can be readily used in practice, for the scope of this work (12) is preferred because the location of the points of contra-flexure in the columns are used for including the dynamic effects as explained in the next section. The reference static capacity-based shear demand, $V_{o, c}$, is defined for the case where the points of contraflexure are located at the mid-length of the columns, such that $l_{i, c}^{B}=l_{c}^{B} / 2$ and $l_{i, c}^{T}=l_{c}^{T} / 2$, where $l_{c}^{B}$ and $l_{c}^{T}$ are the length of the bottom and top columns measured to the centrelines of the beams. Replacing these terms into (12) leads to (25):

$$
V_{o, c}=\frac{M_{o, b}^{L}+M_{o, b}^{R}}{\left(l_{c}^{T}+l_{c}^{B}\right) / 2}
$$

For the particular case where $l_{c}^{B}=l_{c}^{T}=h_{s}$, with $h_{s}$ the typical storey height, (25) becomes (26):

$$
V_{o, c}=\frac{M_{o, b}^{L}+M_{o, b}^{R}}{h_{s}}
$$

A reduced value of $l_{i, c}^{T}$ and/or $l_{i, c}^{B}$ from the reference value defined above implies an increase in the shear demand. This effect is accounted for via the estimation of the maximum dynamic amplification of the elastic moments in the columns as explained later on the paper.

\section{Columns of the first storey}

For columns of the first level, the capacity-based shear required by NZS3101 (2006) is conservatively taken as if the column would develop its flexural overstrength at both ends, and further amplified by a factor of 1.15 , acknowledging the catastrophic consequences of shear failure in the columns of the first storey. The required shear force for such columns is presented in (27):

$$
V_{c a p}^{l s t}=\frac{1.15\left(M_{o, c}^{B}+M_{o, c}^{T}\right)}{L_{n}}
$$

where $L_{n}$ is the clear height of the column, and $M_{o, c}^{T}$ and
$M_{o, c}^{B}$ are calculated with the axial load consistent with the inelastic mechanism (i.e. static loads plus the shear forces developed in the beams of all the storeys, see Figure 1). No dynamic amplification factors are required for this case.

\section{Sources of overstrength}

According to ACI318 (2019), the resisting moments of the beams at overstrength should be taken as the (maximum) 'probable' moments $M_{p r}^{L}$ and $M_{p r}^{R}$ and as the nominal moments $M_{o, b}^{L}=M_{n, b}^{L}$ and $M_{o, b}^{R}=M_{n, b}^{R}$ for intermediate frames. The probable moments are calculated with a yielding stress of the steel amplified by 1.25 times. Even though it is not totally clear what is the criteria for such increase, the fundamentals of capacity-based formulations claim for overstrength due to: (1) the inherent increase in the actual value of $f_{y}$ compared to the specified nominal (characteristic) value, occurring at $\varepsilon_{y}$ axial deformation levels $(0.2 \%$ for Grade 60 steel); and (2) and increase in the resisting stress of the reinforcing steel due to strain hardening effects, normally occurring at approximately $1 \%$ axial deformation (Park, 1996). According to Park (1996) and Andriono and Park (1986), for New Zealand steel, an increase of $17 \%$ should be expected for the real/nominal yielding stress effect, and of $8 \%$ due to strain hardening, summing up the $25 \%$ increase stipulated by ACI318. This effect is also included in NZS3101 (2006), section 2.6.5.5, but in a slightly different way which requires multiplying the nominal strength directly by $\phi_{0}=1.25$. Given the nature of the main source for overstrength of $f_{y}$, which occurs at small deformations, it could be argued that this effect should also be accounted for in intermediate frames of ACI318, if the justification of using $M_{n}$ instead of $M_{p r}$ is the smaller deformations they would suffer. Thus, is proposed that a factor in the order of 1.17 is used for intermediate frames, or a value for a specific reinforcing steel type, following procedures such as those used in Andriono and Park (1986).

\section{Dynamic magnification of static shear}

Non-linear dynamic analyses of wall-frame and frameonly structures have showed that the static capacitybased shear force calculated with (12) is amplified due to dynamic effects (Paulay, 1983; Goodsir et al., 1983; Paulay and Goodsir, 1986; Paulay and Priestley, 1992; Paulay, 1996; Priestley et al., 2007). This amplification is related 
to the dynamic magnification of the flexural moments in the column due to the effect of higher modes of vibration. Recalling that column-hinging is to be avoided above the ground level, the elastic moments developed at the ends of a column must firstly be multiplied by the overstrength factor $\Omega_{0, c}$. This is, the top and bottom column moments at flexural over-strength of the beams are given by equations (28) and (29), respectively.

$$
\begin{aligned}
& M_{o, c}^{T}=\Omega_{0, c} M_{E, c}^{T} \\
& M_{o, c}^{B}=\Omega_{0, c} M_{E, c}^{B}
\end{aligned}
$$

Due to dynamic effects, such moments should be multiplied by the dynamic amplification factor $\omega_{f}$ (Paulay and Priestley, 1992; Priestley et al., 2007), such that the capacity-based column moments are obtained with (30) and (31).

$$
\begin{aligned}
& M_{c a p, c}^{T}=\omega_{f} \Omega_{0, c} M_{E, c}^{T} \\
& M_{c a p, c}^{B}=\omega_{f} \Omega_{0, c} M_{E, c}^{B}
\end{aligned}
$$

As the shear in the top and bottom columns is the same, if $l_{i, c}^{B}=l_{i, c}^{T}$, it also holds that $M_{c a p, c}^{B}=M_{\text {cap }, \mathrm{c}}^{T}=M_{c a p, c}$ and $M_{E, c}^{B}=$ $M_{E, c}^{T}=M_{E, c}$, which leads to the generic form of (32):

$$
M_{c a p, c}=\omega_{f} \Omega_{0, c} M_{E, c}
$$

Note that the original expression for $M_{c a p, c}$ proposed in Paulay and Priestley (1992) includes the factor $\Omega_{0, c}=\Omega_{0, b}$, appropriate for the generic symmetrical case.

Figure 2 presents the moment diagram of an isolated column of intermediate storeys consistent with: (1) the development of the overstrength moments in the beams of both sides and both ends of the column; and (2) same as (1), but including moment amplification due to dynamic effects at the top of the column only. The first case corresponds to the maximum static shear (reference capacity-based shear demand) and the second is related to the moment magnification factor $\omega_{f}$ as explained in the following. In Figure 2(a), the superscripts $n$ and $n+1$ in the columns and beam forces and moments refer to the storey $n$ and $n$ +1 , respectively. The bending moment diagrams of Figure 2(b) are referred to the centrelines of the columns, but they can easily be referred to the beam faces. The inflexion points are identified by $l_{i, c}^{n}$ for the reference case, and by $l_{i, c}^{n, \omega}=l_{i, c}^{n} / \omega_{v}$ for the case including dynamic magnification of $M_{E, c}^{T, n}$, with $\omega_{v}>1$, the dynamic magnification factor for shear. To obtain an expression for $\omega_{v}$ as a fuction of $\omega_{f}$, the reduced location of the point of contraflexure is related a)

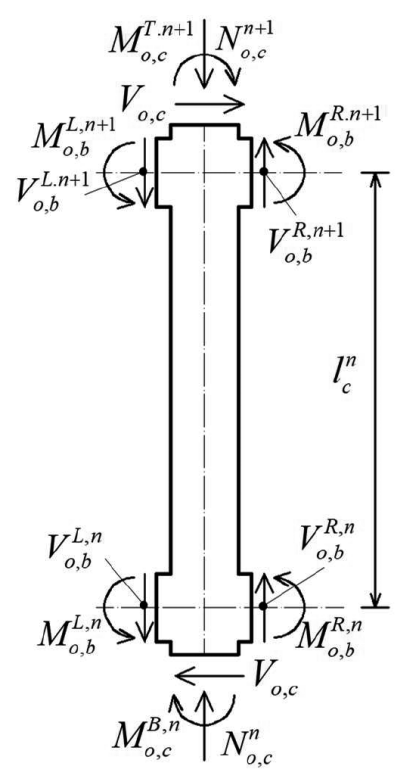

b)

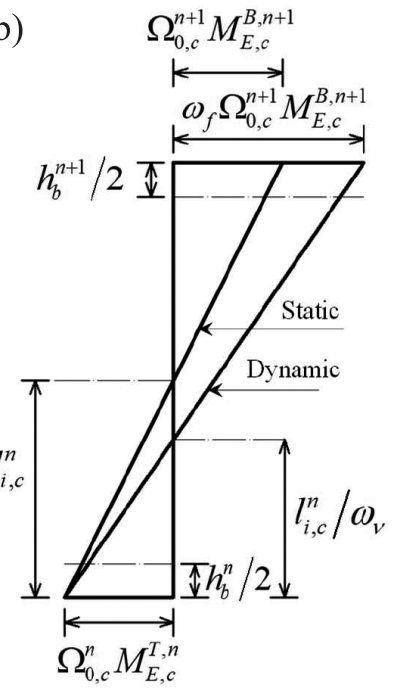

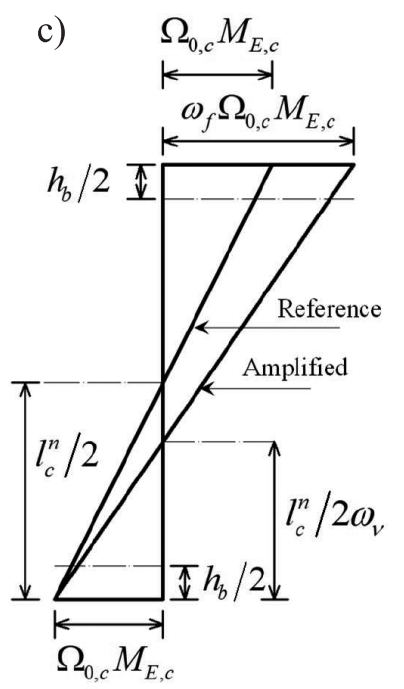

Figure 2: Dynamic amplification of shear in columns: a) equilibrium in an isolated column, b) bending moment diagrams at overstrength and dynamic amplification and c) bending moment diagram used for deriving $\omega_{v}$ 
to the static reference counterpart $l_{i, c}^{n}=l_{c}^{n} / 2$ (column midlength), implying that $M_{o, c}^{B, n+1}=M_{o, c}^{T, n}=M_{o, c}$ and $\Omega_{0, c}^{n+1}=\Omega_{0, c}^{n}=$ $\Omega_{0, c}$, as shown in Figure 2(c).

With reference in Figure 2(c), the shear in the column (slope of the bending moment diagram) corresponding to the amplified case is:

$$
V_{c a p, c}=\frac{\Omega_{0, c} M_{E, c}\left(1+\omega_{f}\right)}{l_{c}^{n}}
$$

The location of the associated point of contraflexure $l_{i, c}^{n, \omega}$ is given by (34):

$$
l_{i, c}^{n, \omega}=\frac{l_{c}^{n}}{\left(1+\omega_{f}\right)}=\frac{l_{c}^{n}}{2} \frac{2}{\left(1+\omega_{f}\right)}
$$

By definition, $l_{i, c}^{n, \omega}=\left(l_{c}^{n} / 2\right) / \omega_{v}$, which replaced in the left hand side of (34) leads to:

$$
\omega_{v}=\frac{\left(1+\omega_{f}\right)}{2}
$$

Equation (35) relates the shear amplification factor $\omega_{v}$ and the moment magnification $\omega_{f}$ for the particular case illustrated in Figure 2(c). The minimum and maximum values for $\omega_{f}$ proposed by Paulay and Priestley (1992) and adopted in NZS3101 (2006) are $\omega_{\min }=1.3$ and $\omega_{\max }=1.8$, respectively, under unidirectional loading (if bi-directional effects are included these values are larger). Replacing the maximum value $\omega_{f}=1.8$ in (35) leads to $\omega_{v}=1.4$. On the other hand, if $\omega_{\max }=1.3$ is used, then $\omega_{v}=1.15$. Taking the average of both values, leads to $\omega_{v}=1.275 \approx$ 1.3 , the dynamic amplification recommended by Paulay and Priestley (1992) and stipulated in the code NZS3101. Note that the value $\omega_{v}=1.15$ corresponds to the additional factor used for amplifying the shear in the columns of the first storey (see equation (27)), even though it is not explicitly mentioned in NZS3101, and may be considered a coincidence.

To obtain a general expression for the capacity-based shear demands including dynamic effects, with reference to Figure 1, the shear associated to the reduced inflection point lengths $l_{i, c}^{T, \omega}$ and $l_{i, c}^{B, \omega}, V_{c a p, c}$, is expressed as in (36), which is analogous to (12):

$$
V_{c a p, c}=\frac{M_{o, b}^{L}+M_{o, b}^{T}}{l_{i, c}^{T, \omega}+l_{i, c}^{B . \omega}}
$$

Herein, it is considered that the reference locations of the points of contraflexure in the columns above and below joint are both affected by dynamic amplifications, such that $l_{i, c}^{T, \omega}=l_{i, c}^{T} / \omega_{v}$ and $l_{i, c}^{B, \omega}=l_{i, c}^{B} / \omega_{v}$. Replacing these expressions in (36) leads to (37):

$$
V_{c a p, c}=\omega_{\nu} \frac{M_{o, b}^{L}+M_{o, b}^{T}}{l_{i, c}^{T}+l_{i, c}^{B}}
$$

Dividing (37) by (12) yields (38), the capacity-based shear demand in the column accounting for dynamic effects.

$$
V_{c a p, c}=\omega_{\nu} V_{o, c}
$$

Finally, combining (38) and (13) leads to:

$$
V_{c a p, c}=\omega_{v} \Omega_{o, c} V_{E, c}
$$

Equation (39) has the form of the equation proposed by Paulay and Priestley (1992) and adopted by NZS3101, but uses $\Omega_{0, c}$ instead of $\Omega_{0, b}^{\text {avg }}$ and $\omega_{v}$ can be different to 1.3.

\section{Case study definition and calculated shear demands in columns}

\section{Prototype structure description}

The prototype structure used in this work (Figure 3) comprises of an ideal 12-storey RC building, $45.15 \mathrm{~m}$ high (first level $5 \mathrm{~m}$, all others $3.65 \mathrm{~m}$ ), and with a rectangular plan layout extending $55.3 \mathrm{~m}$ (7 bays at $7.9 \mathrm{~m}$ ) and 20.1 $\mathrm{m}$ ( 3 bays at $6.7 \mathrm{~m}$ ) in the long and short dimension, respectively. The seismic and gravity load resisting system comprises of four cantilever T-shaped walls and frames located in the perimeter and the central part of the structure, as shown in Figure 3(a). The floor system consisted of 200 $\mathrm{mm}$ slabs. The structure was designed following the codes NCh433 (1996) and ACI318 (2005).

The walls were $500 \mathrm{~mm}$ and $300 \mathrm{~mm}$ thick in the short and long directions, respectively, which correspond to the web and the flange of the T-shaped cross-section, respectively. The columns had a square cross-section of $550 \times 550 \mathrm{~mm}$ (except for the first storey central columns with 650x650 
a)

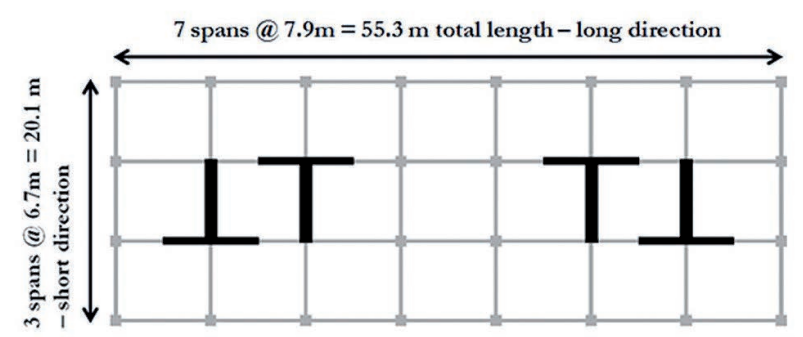

T-shaped walls: Web $500 \mathrm{~mm}$, Flange $300 \mathrm{~mm}$ thick, $45 \mathrm{~m}$ high

b)

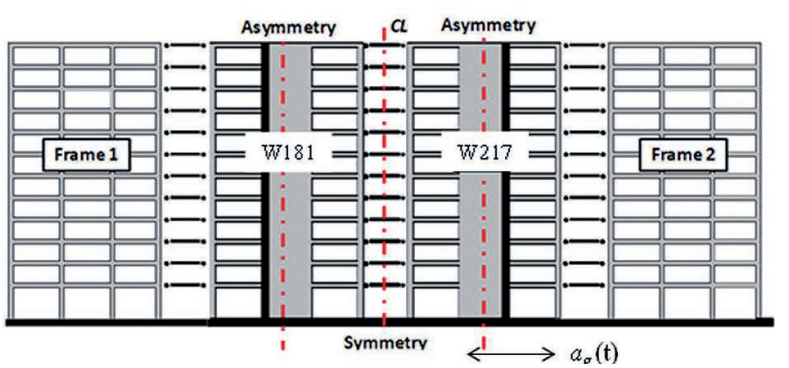

Figure 3: Prototype structure: (a) plan layout; (b) short dimension model simplification

$\mathrm{mm}$ ), whereas the beams had a rectangular cross-section of $600 \times 250 \mathrm{~mm}$. It was assumed that the concrete had a characteristic compressive strength of $f_{c}^{\prime}=30 \mathrm{MPa}$, and the reinforcing steel had yielding and ultimate stresses of $f_{y}=420 \mathrm{MPa}$ and $f_{u}=630 \mathrm{MPa}$, respectively. The structure was analysed in the short direction, and further idealized, making use of symmetry, as that presented in Figure 3(b).

\section{Calculated shear demands for columns}

Table 1 presents the reference shear demands for four column types (CT1 to CT4). Columns type CT1 and CT2 correspond to exterior and interior columns of the external frame (Frame 1), respectively, whereas columns type CT3 and CT4 correspond to the exterior and interior columns of the internal frame (Frame 2), respectively. For the scope of this investigation, the reference shear $V_{o, c}$ is calculated with the nominal moment capacities of the beams, acknowledging that this was the value used as input for the numerical model, as the main source for overstrength is associated to variations in the yielding stress used in the derivation of the beam flexural resistances, which can be included separately. Strain hardening effects are accounted for with the inclusion of a post-yielding stiffness. Table 1 summarizes the nominal moments of the beams (type 2A and $2 \mathrm{~B}$ for Frame 1 and Frame 2, respectively), and the associated values of $V_{o, c}$ per equation (12).

For the sake of comparison, the shear demand calculated referring the nominal moments of the beams to the faces of the column is also considered, which is equivalent to not neglecting the resisting contribution of the shear forces in the beams as in (8). This second reference shear, $V_{o, c}^{*}$, is calculated with (40).

Table 1: Reference static capacity-based shear demand

\begin{tabular}{|c|c|c|c|c|c|}
\hline $\begin{array}{c}\text { Column } \\
\text { type }\end{array}$ & $\begin{array}{c}\text { Beam } \\
\text { type }\end{array}$ & $\begin{array}{c}M_{\mathrm{o}, \mathrm{b}}^{L}, \\
\mathrm{kNm}\end{array}$ & $\begin{array}{c}M_{\mathrm{o}, \mathrm{b}}^{R}, \\
\mathrm{kNm}\end{array}$ & $\begin{array}{c}V_{o, c}^{*}, \\
\mathrm{kN}\end{array}$ & $\begin{array}{c}V_{o, c}^{*}, \\
\mathrm{kN}\end{array}$ \\
\hline $\mathrm{CT} 1$ & 2A & 320 & - & 88 & 81 \\
\hline $\mathrm{CT} 2$ & 2A & 320 & 175 & 136 & 125 \\
\hline $\mathrm{CT} 3$ & 2B & 440 & - & 120 & 110 \\
\hline $\mathrm{CT} 4$ & 2B & 440 & 250 & 189 & 174 \\
\hline
\end{tabular}

$$
V_{0, c}^{*}=\frac{\left(M_{o, b}^{L}+M_{0, b}^{R}\right)\left(1-h_{c} / l_{b}\right)}{l_{c}}
$$

The shear obtained with (40) is smaller than obtained with (12). In the case of the example under investigation, $h_{c}=$ $0.55 \mathrm{~m}$ and $l_{b}=6.7 \mathrm{~m}$, implying a reduction factor of $V_{o, c}$ equal to $\left(1-h_{c} / l_{b}\right)=0.92$.

\section{Numerical modelling and procedure}

A finite element model constructed with lumped inelasticity macro-elements in Ruaumoko2D (Carr, 2016) was used for the NLDA. The SINA hysteresis model (Saiidi and Sozen, 1979) was used for the T-shaped walls, as it allows for different stiffness and strength depending on the direction of movement, and includes pinching effects. The modified Takeda model (Saidii and Sozen, 1979) was used for beams and column elements. The unloading and reloading parameters for the hysteresis of the frame members were set to $\alpha=0.2$ and $\beta=0.3$, respectively, representing intermediate unloading and reloading stiffness degradation conditions; see Quintana Gallo (2008) for further details.

A set of 13 earthquake records, listed in Table 2, was used for the analyses. Such records do not respond to any scaling in amplitude or frequency, and are intended to represent different possible scenarios that the structure could be subjected to. The strong ground motions were recorded in different parts of the world, but mostly in Chile and New Zealand. The raw data of the records was corrected following the recommendations of Boore and Bommer (2005). Table 2 also presents the peak ground acceleration PGA and 
velocity PGV, the significant duration $D_{s}$ (Trifunac and Brady, 1975), and the Arias Intensity AI of the earthquake records. The significant duration is taken from 5 to $95 \%$ of AI. Additional information on the characteristics of the input motions and associated earthquake events can be found in Quintana Gallo $(2008,2014)$.

Table 2: Earthquake records information

\begin{tabular}{|c|c|c|c|c|c|c|c|}
\hline ID & Earthquake & Station & Comp. & $\begin{array}{c}\text { PGA, } \\
\mathrm{g}\end{array}$ & $\begin{array}{c}\mathrm{PGV}, \\
\mathrm{m} / \mathrm{s}\end{array}$ & $\begin{array}{c}D_{s}, \\
\mathrm{~s}\end{array}$ & $\begin{array}{l}\mathrm{AI}, \\
\mathrm{m} / \mathrm{s}\end{array}$ \\
\hline EQ1 & $\begin{array}{l}\text { Littleton } 2011 \\
\text { New Zealand }\end{array}$ & $\begin{array}{c}\text { Christchurch } \\
\text { Botanic } \\
\text { Gardens (CBGS) }\end{array}$ & H1 & 0.53 & 0.63 & 9.7 & 2.7 \\
\hline EQ2 & $\begin{array}{l}\text { Littleton } 2011 \\
\text { New Zealand }\end{array}$ & $\begin{array}{l}\text { Christchurch City } \\
\text { Council (CCCC) }\end{array}$ & H1 & 0.36 & 0.66 & 10.6 & 2.4 \\
\hline EQ3 & $\begin{array}{l}\text { Littleton } 2011 \\
\text { New Zealand }\end{array}$ & $\begin{array}{l}\text { Christchurch } \\
\text { Hospital } \\
\text { (CHHC) }\end{array}$ & $\mathrm{H} 2$ & 0.71 & 0.87 & 9.0 & 3.6 \\
\hline EQ4 & $\begin{array}{l}\text { Littleton } 2011 \\
\text { New Zealand }\end{array}$ & $\begin{array}{l}\text { Christchurch } \\
\text { Resthaven } \\
\text { (REHS) }\end{array}$ & H1 & 0.48 & 0.71 & 11.3 & 2.7 \\
\hline EQ5 & $\begin{array}{l}\text { Maule } 2010 \\
\text { Chile }\end{array}$ & $\begin{array}{c}\text { Concepción Centro } \\
\text { (CCC) }\end{array}$ & NS & 0.47 & 0.66 & 57.8 & 10.6 \\
\hline EQ6 & $\begin{array}{l}\text { Maule } 2010 \\
\text { Chile }\end{array}$ & San Pedro (SNP) & $\mathrm{X}$ & 0.59 & 0.47 & 73.8 & 14.3 \\
\hline EQ7 & $\begin{array}{l}\text { Maule } 2010 \\
\quad \text { Chile }\end{array}$ & $\begin{array}{l}\text { Viña del Mar } \\
\text { Marga Marga } \\
\text { (VMM) }\end{array}$ & EW & 0.35 & 0.45 & 32.2 & 4.3 \\
\hline EQ8 & $\begin{array}{l}\text { Maule } 2010 \\
\text { Chile }\end{array}$ & $\begin{array}{c}\text { Concepción Centro } \\
(\mathrm{CCC})\end{array}$ & EW & 0.37 & 0.57 & 60.1 & 6.0 \\
\hline EQ9 & $\begin{array}{c}\text { Kobe } 1995 \\
\text { Japan }\end{array}$ & $\begin{array}{c}\text { Japan } \\
\text { Meteorological } \\
\text { Center (JMA) }\end{array}$ & NOOE & 0.81 & 0.82 & 8.4 & 8.4 \\
\hline EQ10 & $\begin{array}{c}\text { Northridge } \\
1994 \\
\text { USA } \\
\end{array}$ & $\begin{array}{c}\text { Sylmar - County } \\
\text { hospital } \\
\text { parking (SYL) }\end{array}$ & NOOE & 0.84 & 1.29 & 5.3 & 5.0 \\
\hline EQ11 & $\begin{array}{l}\text { Michoacán } \\
1985 \\
\text { Mexico }\end{array}$ & $\begin{array}{c}\text { Secretaria de } \\
\text { Comunicaciones } \\
\text { y Transportes } \\
\text { (SCT) }\end{array}$ & EW & 0.18 & 0.62 & 27.0 & 2.3 \\
\hline EQ12 & $\begin{array}{l}\text { Valparaiso } \\
1985 \\
\text { Chile }\end{array}$ & Llolleo (LLO) & N10E & 0.70 & 0.35 & 35.8 & 15.2 \\
\hline EQ13 & $\begin{array}{l}\text { Valparaíso } \\
1985 \\
\text { Chile }\end{array}$ & $\begin{array}{l}\text { Viña del Mar } \\
\text { Marga Marga } \\
\text { (VMM) }\end{array}$ & NS & 0.34 & 0.32 & 45.0 & 5.5 \\
\hline
\end{tabular}

Figure 4 presents the acceleration (SA) and displacement (SD) response spectra of the 13 earthquake records for a damping ratio of $5 \%$. As a reference, the figure also shows the elastic design spectra prescribed by $\mathrm{NCh} 433$, updated per DS61 (2011), and NZS1170.5 (2004). Such spectra are not reduced by the reduction factors $R^{*}$ and $k_{\mu}$ required by the former and latter standards, respectively. Both design spectra were constructed for a PGA $\left(\mathrm{A}_{0}\right.$ in $\mathrm{NCh} 433$ and $\mathrm{Z}$ in NZS1170.5) of $0.4 \mathrm{~g}$, and for soft soil type D (both standards). The importance factor I of NCh433, as well as the near fault-factor $\mathrm{N}(T, D)$ of NZ1170.5 were taken as 1.0.

Additionally, Figure 4 presents the spectra associated to a maximum credible earthquake (MSE) hazard scenario prescribed by NZS1170.5 (2006), associated to a probability of exceedance of $2 \%$ in 50 years instead of $10 \%$ in 50 years as the design counterpart, as specified in AS/NZS1170.0 (2002). Such difference between both spectra is included via the factor $R_{u}$, which is 1.0 and 1.8 for design and MCE scenarios, respectively.

a)
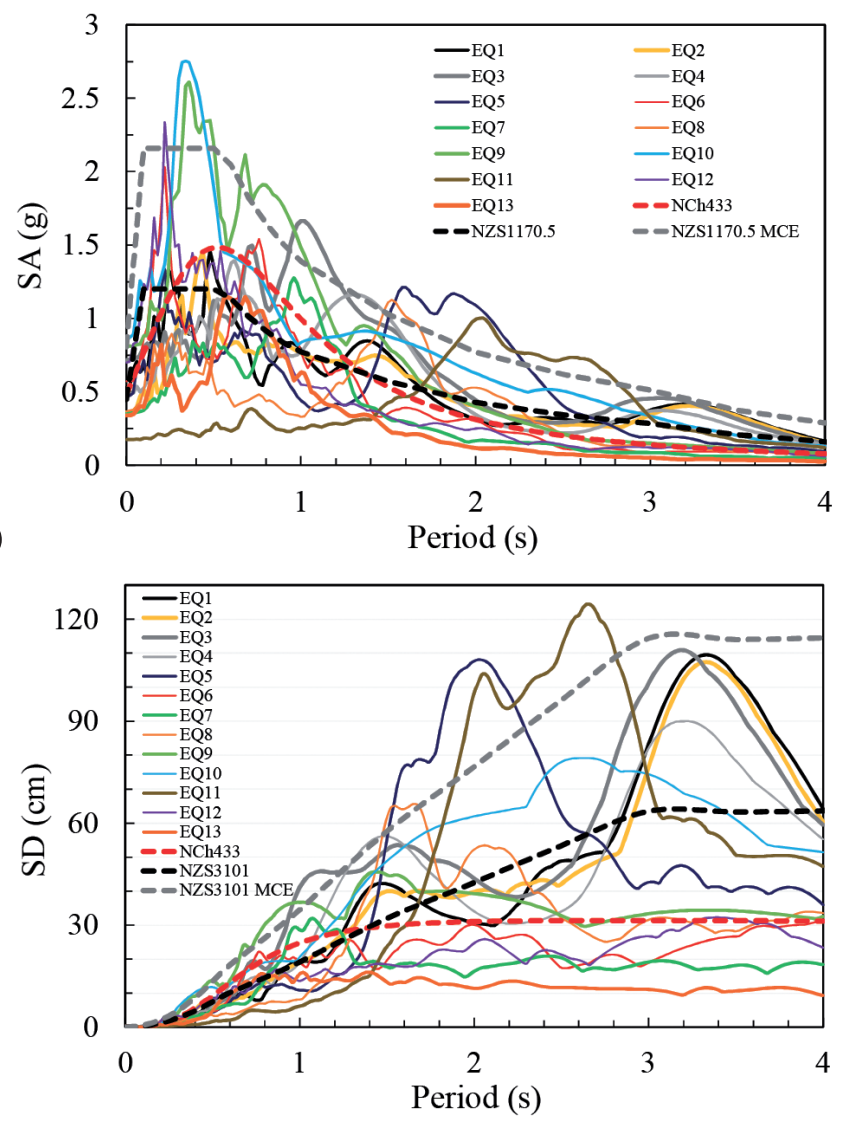

Figure 4: Response spectra of earthquake records and design spectra of NCh433 and NZS1170.5: a) acceleration and b) displacement

Additionally, Figure 4 presents the spectra associated to a maximum credible earthquake (MSE) hazard scenario prescribed by NZS1170.5 (2006), associated to a probability of exceedance of $2 \%$ in 50 years instead of $10 \%$ in 50 years as the design counterpart, as specified in AS/NZS1170.0 (2002). Such difference between both spectra is included via the factor $R_{u}$, which is 1.0 and 1.8 for design and MCE scenarios, respectively. 


\section{Results and discussion}

The graphs of Figure 5 show the values of the dynamic amplification factor $\omega_{v}$ referred to $V_{o, c}$, i.e. calculated with (12), obtained with the set of 13 NLDA. Such values are presented for each column type (CT1 to CT4) and storey level of all the intermediate storeys (\#2 to \#11). In general, the magnitude of $\omega_{v}$ appears to depend on the input motion, but not to a great extent in some of the cases, such as for column CT1 storey \#9. There is not a substantial difference between the results obtained for the four column cases. Figure 5 shows that $\omega_{v}$ was larger than 1.0 for most of the records, column types, and storey levels, with the exception of storeys \#1 and \#11. On the other hand, $\omega_{v}$ was smaller than 1.3 (the threshold required by NZS3101) in the great majority of the cases. However, there are a few cases where this value is exceeded, such that $\omega_{v}$ reaches values as large as 1.6 (CT1, storey \#6).
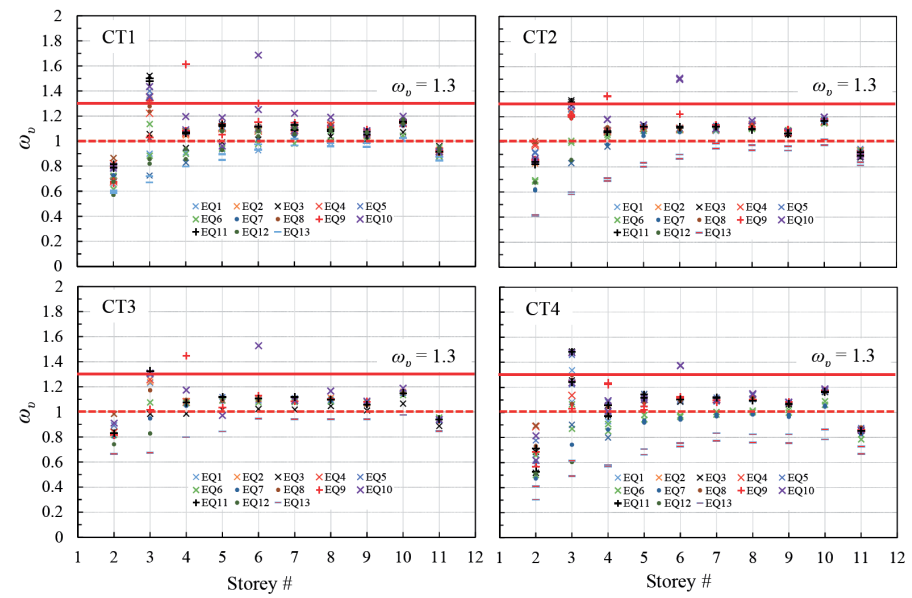

Figure 5: Dynamic amplification factors of shear demands, reference: $V_{o, c}$, for column types CT1 to CT4

The graphs of Figure 6 present the dynamic amplification factor calculated with reference to $V_{o, c}^{*}$ determined with (40), referred to as $\omega_{v}^{*}$. These graphs depict the corresponding magnitude of the dynamic amplification when referred to the less conservative calculation of the static capacity-based shear demands. Under this conditions, it holds that $\omega_{v}^{*}>1.0$ and $\omega_{v}^{*}>1.3$ in a larger number of cases compared to $\omega_{v}$.

To better visualize the dependence of $\omega_{v}$ on a ground motion intensity parameter, the values of $\omega_{v}$ obtained for CT1 plotted against the PGA of the input motion, for each storey level, are presented in Figure 7. The results reflect no apparent correlation between both parameters. For storey $\# 10$, for example, $\omega_{v}$ takes approximately the same value (1.15) independently of the PGA of the input motion, ranging from $0.17 \mathrm{~g}$ to $0.8 \mathrm{~g}$. In fact, this is true for most of the storeys levels. Further studies on the dependence of $\omega_{v}$ on other typically used intensity measures are not pursued and are considered out of the scope of this study. Instead, focus is placed on the evaluation $\omega_{v}=1.3$ as a conservative limit independent of the input motion.

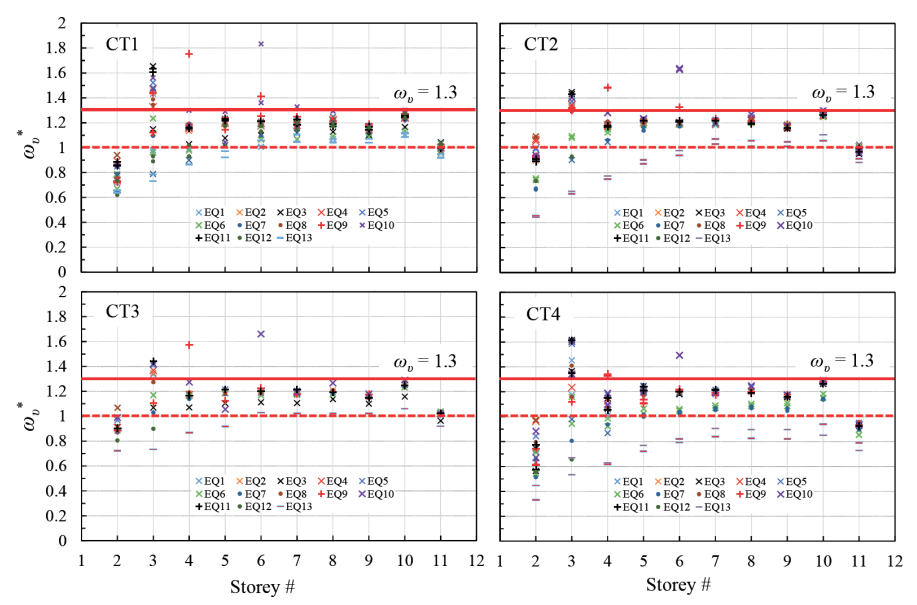

Figure 6: Dynamic amplification factors of shear demands, reference: $V_{o, c}^{*}$

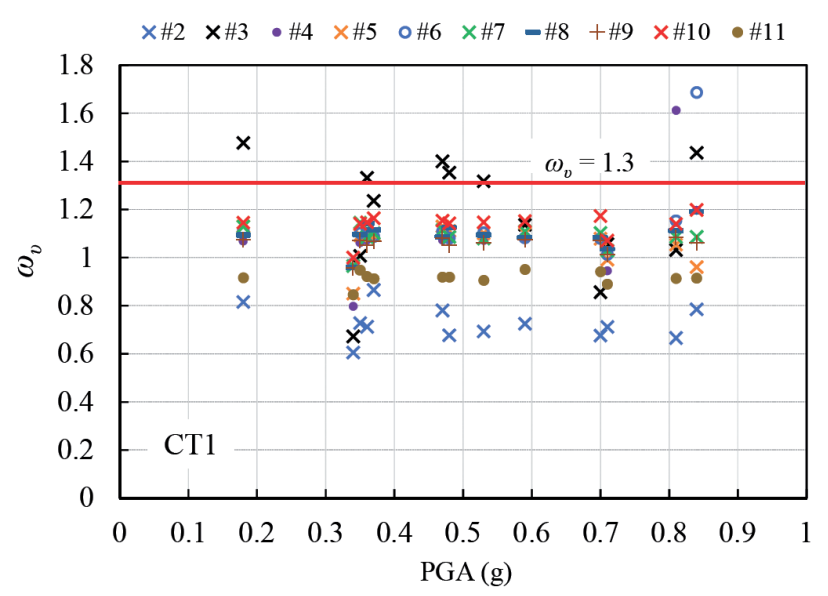

Figure 7: Dynamic amplification factor $\omega_{\mathrm{v}}$ versus PGA of input motion

Table 3 presents the percentage of the total cases where $\omega_{v}$ and $\omega_{v}^{*}$ exceed 1.0 and 1.3 , denoted by $P_{1.0}, P_{1.3}$, and $P_{1.0}^{*}$ and $P_{1.3}^{*}$, respectively, for columns CT1 and CT2. Table 3 shows that $\omega_{v}$ exceeded 1.0 in the great majority of the cases for storeys \#3 to \#10 (73\% of cases or more), whereas for storeys \#2 and \#11 in only up to $8 \%$ of the cases. On the other hand, it shows that the predicted values of $\omega_{v}$ were larger than 1.3 only in storeys \#3, \#4, and \#6, with a maximum of $42 \%$ of the cases exceeding such threshold. For both columns $\omega_{v}^{*}$ exceeded 1.0 in all of the 
Table 3: Percentage of cases where thresholds 1.0 and 1.3 are exceeded, CT1 and CT2

\begin{tabular}{|c|c|c|c|c|c|c|c|c|}
\hline \multirow{2}{*}{$\begin{array}{c}\text { Storey } \\
\#\end{array}$} & \multicolumn{4}{|c|}{ CT1 } & \multicolumn{4}{c|}{ CT2 } \\
\cline { 2 - 9 } & \multicolumn{2}{|c|}{$\omega_{v}$} & \multicolumn{2}{|c|}{$\omega_{v}^{*}$} & \multicolumn{2}{|c|}{$\omega_{v}$} & \multicolumn{2}{c|}{$\omega_{v}^{*}$} \\
\cline { 2 - 10 } & $P_{1.0} \%$ & $P_{1.3}, \%$ & $P_{1.0}^{*}, \%$ & $P_{1.3}^{*}, \%$ & $P_{1.0}, \%$ & $P_{1.3} \%$ & $P_{1.0}^{*} \%$ & $P_{1.3}^{*}, \%$ \\
\hline 2 & 0 & 0 & 0 & 0 & 8 & 0 & 15 & 0 \\
\hline 3 & 73 & 42 & 73 & 54 & 73 & 15 & 77 & 62 \\
\hline 4 & 69 & 4 & 77 & 8 & 77 & 8 & 85 & 8 \\
\hline 5 & 69 & 0 & 92 & 0 & 85 & 0 & 88 & 0 \\
\hline 6 & 85 & 8 & 100 & 12 & 92 & 8 & 92 & 15 \\
\hline 7 & 88 & 0 & 100 & 4 & 92 & 0 & 100 & 0 \\
\hline 8 & 88 & 0 & 100 & 0 & 92 & 0 & 100 & 0 \\
\hline 9 & 88 & 0 & 100 & 0 & 92 & 0 & 100 & 0 \\
\hline 10 & 96 & 0 & 100 & 4 & 96 & 0 & 100 & 8 \\
\hline 11 & 0 & 0 & 35 & 0 & 0 & 0 & 19 & 0 \\
\hline All & 66 & 5 & 78 & 8 & 71 & 3 & 78 & 9 \\
\hline
\end{tabular}

cases for storeys \#7 to \#10, and in $73 \%$ and $35 \%$ or more of the cases for storeys \#3 to \#6, and storeys \#2 and \#11, respectively. In turn, the variable $\omega_{v}^{*}$ exceeded 1.3 only in storeys $\# 3$, \#4, \#6, and $\# 10$, with a maximum of $62 \%$ of the cases for $\mathrm{CT} 1$ and storey \#3.

The average values of $P_{1.0}, P_{1.3}$, and $P_{1.0}^{*}$, and $P_{1.3}^{*}$ obtained for all the storeys are very similar for both columns CT1 and CT2. In the particular case of $P_{1.3}$, average values of $5 \%$ and 3\% were obtained, which is rather low. On the other end, the average values of $P_{1.0}^{*}$ indicate that $\omega_{v}^{*}$ exceeded 1.0 in $78 \%$ of the cases for CT1 and CT2, which is rather high. While the latter index indicates that dynamic amplification existed in most of the cases if $V_{o, c}^{*}$ is used in the calculations of the static reference shear, the former suggests that the use of $V_{o, c}$ with $\omega_{v}=1.3$ is 'appropriate enough' for use in practice. This is, from a statistical inference point of view, there exists only a limited number of unfavourable cases. What is "acceptable" is a matter of discussion, but, as proposed by Rudner (1953), such definition seems to rely on ethical considerations. Further, such ethical considerations may be related to how unbeneficial are the anticipated consequences of exceeding the accepted limit.

Table 4 presents the values of $P_{1.0}, P_{1.3}, P_{1.0}^{*}$, and $P_{1.3}^{*}$ for columns CT3 and CT4. The results show that for these column types, the number of cases where $\omega_{v}$ exceeded 1.0 was smaller than for CT1 and CT2 (see Table 2). For CT3, $\omega_{v}$ and $\omega_{v}^{*}$ were larger 1.0 in $50 \%$ of the cases or less for all the storey levels, whereas for CT4, these variables exceeded 1.0 in $92 \%$ of the cases for storey $\# 10$, for example. The average of the results obtained for the individual storeys show that $\omega_{v}=1.3$ was exceeded in only 1 and $3 \%$ of the cases, meaning that the associated formulation is unconservative, in average over the storeys, in only $5 \%$ or less of the cases considering each individual columns separately.

Table 4: Percentage of cases where thresholds 1.0 and 1.3 are exceeded, CT3 and CT4

\begin{tabular}{|c|c|c|c|c|c|c|c|c|}
\hline \multirow{2}{*}{$\begin{array}{c}\text { Storey } \\
\#\end{array}$} & \multicolumn{4}{|c|}{ CT3 } & \multicolumn{4}{c|}{ CT4 } \\
\cline { 2 - 9 } & \multicolumn{2}{|c|}{$\omega_{v}$} & \multicolumn{2}{|c|}{$\omega_{v}^{*}$} & \multicolumn{2}{|c|}{$\omega_{v}$} & \multicolumn{2}{c|}{$\omega_{v}^{*}$} \\
\hline & $P_{1.0} \%$ & $P_{1.3}, \%$ & $P_{1.0}^{*}, \%$ & $P_{1.3}^{*}, \%$ & $P_{1.0}, \%$ & $P_{1.3}, \%$ & $P_{1.0}^{*}, \%$ & $P_{1.3,}^{*} \%$ \\
\hline 2 & 0 & 0 & 4 & 0 & 0 & 0 & 0 & 0 \\
\hline 3 & 31 & 8 & 31 & 23 & 73 & 27 & 73 & 50 \\
\hline 4 & 31 & 0 & 38 & 0 & 42 & 0 & 69 & 8 \\
\hline 5 & 31 & 0 & 50 & 0 & 69 & 0 & 81 & 0 \\
\hline 6 & 50 & 0 & 50 & 4 & 69 & 8 & 85 & 8 \\
\hline 7 & 50 & 0 & 50 & 0 & 73 & 0 & 92 & 0 \\
\hline 8 & 50 & 0 & 50 & 0 & 77 & 0 & 92 & 0 \\
\hline 9 & 50 & 0 & 50 & 0 & 73 & 0 & 92 & 0 \\
\hline 10 & 50 & 0 & 50 & 0 & 92 & 0 & 92 & 0 \\
\hline 11 & 0 & 0 & 50 & 0 & 0 & 0 & 0 & 0 \\
\hline All & 34 & 1 & 42 & 3 & 57 & 3 & 68 & 7 \\
\hline
\end{tabular}

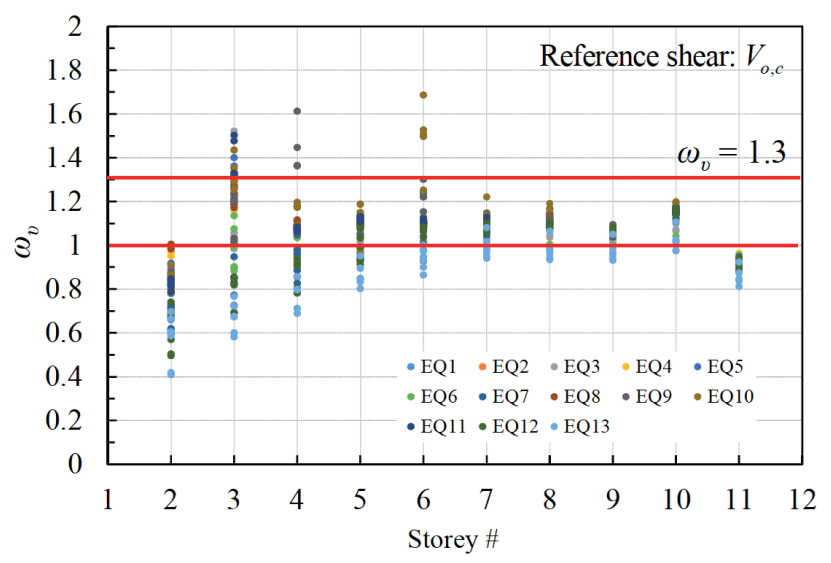

Figure 8: Calculated dynamic amplification factors for $V_{o, c}$ (eq. (12))

To compare shear amplifications factors obtained for all the column types and storey \#, the results presented in Figures 5 and 6 are merged into the graph presented in Figure 8 and 9 , respectively. The results presented in Figure 8 indicate that $\omega_{v}$ takes values larger than 1 and smaller than 1.3 in the majority of the cases. Nevertheless, the limit of 1.3 is exceeded in some of the cases in the columns of the storeys $\# 3$, \#4, and \#6, reaching values as large as 1.7 . Hence, even though appropriate for great majority of the cases, such limit is shown to be unconservative in some of them by 
an important extent. This is also true for the values of $\omega_{v}^{*}$, presented in Figure 9. Table 5 summarizes the percentage of the times where $\omega_{v}$ and $\omega_{v}^{*}$ exceeded 1.0 and 1.3 , , considering all the column types.

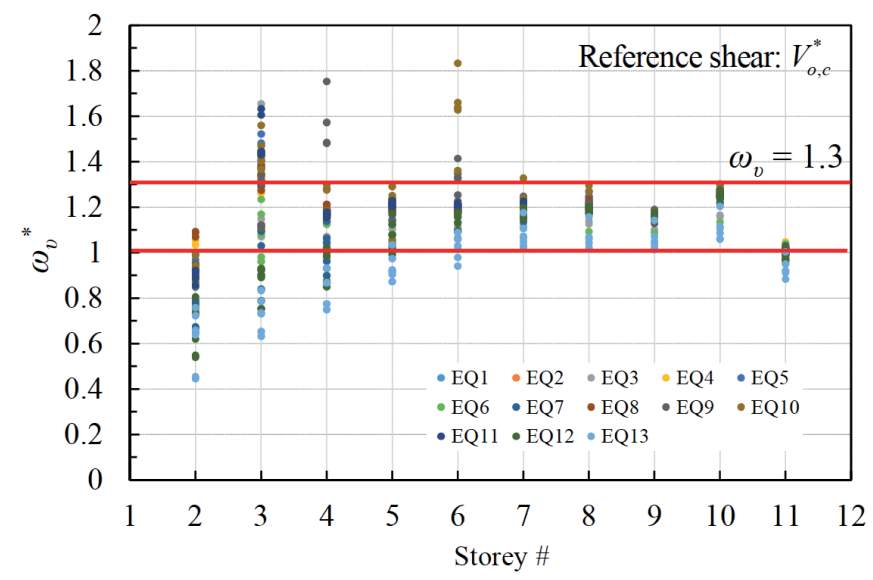

Figure 9: Calculated dynamic amplification factors for $V_{o, c}^{*}$ (eq. (40))

Table 5: Dynamic amplification factors all columns

\begin{tabular}{|c|c|c|c|c|}
\hline \multirow{2}{*}{ Storey \# } & \multicolumn{2}{|c|}{$\omega_{v}$} & \multicolumn{2}{c|}{$\omega_{v}^{*}$} \\
\cline { 2 - 5 } & $P_{1.0}, \%$ & $P_{1.3}, \%$ & $P_{1.0}^{*} \%$ & $P_{1.3}^{*} \%$ \\
\hline 2 & 2 & 0 & 6 & 0 \\
\hline 3 & 71 & 25 & 74 & 53 \\
\hline 4 & 64 & 4 & 79 & 7 \\
\hline 5 & 74 & 0 & 89 & 0 \\
\hline 6 & 86 & 7 & 94 & 11 \\
\hline 7 & 88 & 0 & 98 & 1 \\
\hline 8 & 88 & 0 & 98 & 0 \\
\hline 9 & 88 & 0 & 98 & 0 \\
\hline 10 & 95 & 0 & 98 & 3 \\
\hline 11 & 0 & 0 & 37 & 0 \\
\hline All & 66 & 4 & 77 & 7 \\
\hline
\end{tabular}

Table 5 shows that $\omega_{v}>1.0$ in 71 to $95 \%$ of the cases for storeys \#3 to \#11 considering all the column types. Such amount, on the other hand, is equal to only $2 \%$ of the times for storey $\# 2$ and $0 \%$ for storey $\# 11$. The condition $\omega_{v}=1.3$, in turn, was exceeded only in storeys $\# 3$, \#4, and \#6, with a maximum of $25 \%$ of the cases in the columns of storey $\# 6$. These findings are also true for $\omega_{v}^{*}$, except that the number of cases where the limits are exceeded slightly increases, and that the number of times where $\omega_{v}^{*}>1.3$ reaches as much as $50 \%$ of the cases. Including the results of all the column types, all the storeys and records, $P_{1.0}=66 \%$ and $\mathrm{P}_{1.3}=4 \%$. For $\omega_{v}^{*}$ in turn, $P_{1.0}^{*}=77 \%$ and $P_{1.3}^{*}=7 \%$ of the cases, respectively. If storeys \#2 and \#11 are excluded in the calculation of $P_{1.0}$ and $P_{1.0}^{*}, \omega_{v}>1.0$ and $\omega_{v}^{*}>1.0$ in 82 and $91 \%$ of the cases, respectively, meaning that dynamic amplification of shear is predicted in the large majority of the cases, even using the conservative calculation of the static reference shear of equation (12).

\section{Conclusions}

This work presented a numerical study on the amplification of the shear forces calculated following static capacity-based principles, due to dynamic effects. The paper reviewed the calculations involved in such shear demand and examined the fundamentals of capacity-based design as originally proposed and as recommended in the ACI318 and NZ3101 codes. It was noted that the original methodology as well as the NZS3101 (2006) do require the use of a dynamic amplification factor equal to 1.3 for increasing the shear force in the columns of intermediate storeys (just as includes one for walls), whereas ACI318 (2019) does not. To examine: (1) the existence or not of such amplification effects in columns of RC frames designed per the Chilean code, and (2) the appropriateness of the limit 1.3 prescribed by NZS3101 for such case, the paper presented the calculated dynamic amplification factors $\omega_{v}$ for the columns of two frames of a case study building designed with NCh433 and ACI318, using nonlinear dynamic analyses NLDA with a suit of 13 earthquake records. The results indicated that $\omega_{v}>1.0$ was obtained in $66 \%$ of the cases considering all column types and storeys. However, if the bottom and top intermediate storeys are separated, such percentage increases to $83 \%$, because $\omega_{v}>1.0$ in only $2 \%$ and none of the cases in such storeys. The limit $\omega_{v}>1.3$, on the other hand, was exceeded in only three storey levels, with a maximum of $25 \%$ of the times, and occurring in only $4 \%$ of all the cases. Even though such amount is reduced, values as large as $\omega_{v}>1.6$ were obtained. The results showed no apparent correlation with the PGA of the input motion, used as a seismic intensity measure. It is concluded that, in this case, a dynamic amplification factor $\omega_{v}=1.3$ is appropriate for the calculation of the shear demands associated to capacity-based design considerations for frames.It is recommended that such requirement of the New Zealand standard NZS3101 $\left(\omega_{\mathrm{v}}=1.3\right)$ is included in the new requirements of the Chilean code NCh430, under development at the time of writing this contribution, acknowledging that its conservatism cannot be ensured conclusively. It is thought that the non-inclusion of such provision does not help mitigating the undesired conse- 
quences associated to shear failure of RC columns part of multi-storey frames, which can be quite catastrophic.

\section{References}

ACI318 (2019). Building code requirements for structural concrete and commentary (ACI318M-19). American Concrete Institute, Farmington Hills, USA

ACI318 (2005). Building code requirements for structural concrete and commentary (ACI318M-05). American Concrete Institute, Farmington Hills, USA

ACI318 (1995). Building code requirements for structural concrete and commentary (ACI 318R-95). American Concrete Institute, Farmington Hills, USA

Andriono, T. and Park, R. (1986). Seismic design considerations of the properties of New Zealand manufactured steel reinforcing bars. Bulletin of the New Zealand Society for Earthquake Engineering 19(3), 213-246

AS/NZS1170.0 (2002). Structural design actions: Part 0. General principles. Standards Australia and Standards New Zealand. Wellington, New Zealand

Boore, D. and Bommer, J.J. (2005). Processing of strong-motion accelerograms: needs, options, and consequences. Soil Dynamics and Earthquake Engineering 25(2), 93-115

Carr, A.J. (2016). Ruaumoko user's manual for the 2-dimensional version. Carr Research Limited, Christchurch, New Zealand

DS61 (2011). Reglamento que fija el diseño sísmico de edificios y deroga decreto $\mathrm{n}^{\circ} 117$, de 2010. Decreto Supremo, Ministerio de Vivienda y Urbanismo, Diario Oficial de la República de Chile, $\mathrm{N}^{\circ}$ 40.133, 8-12

Goodsir, W.J., Paulay, T. and Carr, A.J. (1983). A study on the inelastic seismic response of reinforced concrete coupled frameshear wall structures. Bulletin of the New Zealand Society for Earthquake Engineering 16(3), 185-200

NCh433 (1996). Seismic design of buildings. Norma Chilena Oficial. Instituto Nacional de Normalización INN, Santiago, Chile (in Spanish)

NCh430 (2008). Hormigón armado - Requisitos de diseño y cálculo. Norma Chilena Oficial, Instituto Nacional de Normalización INN, Santiago, Chile

NZS1170.5 (2004). Structural design actions: Part 5. Earthquake actions. Standards New Zealand. Wellington, New Zealand

NZS3101 (1995). Design of concrete structures. Standards New Zealand. Wellington, New Zealand
NZS3101 (2006). The design of concrete structures. Standards New Zealand. Wellington, New Zealand

Park, R. (1996). Explicit incorporation of element and structure overstrength in the design process. Proceedings of the 11th World Conference on Earthquake Engineering, Acapulco, Mexico, paper 2130

Paulay, T. (1983). Deterministic seismic design procedures for reinforced concrete buildings. Engineering Structures 5(1), 79-86

Paulay, T. (1996). Seismic design if concrete structures the present needs of societies. Proceedings of the 11th World Conference on Earthquake Engineering, Acapulco, Mexico, paper 2001

Paulay, T. and Priestley, M.J.N. (1992). Seismic design of reinforced concrete and masonry buildings. John Wiley and Sons, New York, USA

Paulay, T. and Goodsir, W.J. (1986). The capacity design of reinforced concrete hybrid structures for multistorey buildings. Bulletin of the New Zealand Society for Earthquake Engineering 19(1), 1-17

Priestley, M.J.N., Kowalsky, M.J. and Calvi, G.M. (2007). Displacement-based seismic design of buildings. IUSS Press, Pavia, Italy

Quintana Gallo, P. (2018). Simple estimation of the maximum elastic roof displacement of a slender cantilever RC wall accounting for dynamic effects. Obras y Proyectos 23, 55-62

Quintana Gallo, P. (2014). The nonlinear dynamics involved in the seismic assessment and retrofit of reinforced concrete buildings. $\mathrm{PhD}$ thesis, University of Canterbury, Christchurch, New Zealand

Quintana Gallo, P. (2008). Analytical evaluation of damage in a reinforced concrete building. MSc thesis, Universidad Técnica Federico Santa María, Valparaíso, Chile (in Spanish)

Rudner, R. (1953). The scientist qua scientist makes value judgements. Philosophy of Science 20(1), 1-6

Saiidi, M. and Sozen, M.A. (1979). Simple and complex models for nonlinear seismic response of reinforced concrete structures. Report UILU-ENG-79-2031, University of Illinois UrbanaChampaign, USA

Trifunac, M.D. and Brady, A.G. (1975). On correlation of seismoscope response with earthquake magnitude and Modified Mercalli Intensity. Bulletin of the Seismological Society of America 65(2), 307-321 